\title{
PRODUTOS DE UM MESTRADO PROFISSIONAL NA ÁREA DA EDUCAÇÃO: UM ESTADO DO CONHECIMENTO \\ http://dx.doi.org/10.5902/2318133840662
}

\author{
Cristiano Lanza Savegnago ${ }^{1}$ \\ Simone da Rosa Messina Gomez ${ }^{2}$ \\ Marilene Gabriel Dalla Corte ${ }^{3}$ \\ Lorena Inês Peterini Marquezan ${ }^{4}$
}

\begin{abstract}
Resumo
Por meio deste estudo objetivou-se identificar e analisar os produtos educacionais decorrentes do Curso de Mestrado Profissional em Políticas Públicas e Gestão Educacional da Universidade Federal de Santa Maria. Trata-se de uma pesquisa exploratória, com base no estado do conhecimento das dissertações disponíveis no repositório digital da UFSM, relativas às turmas que defenderam os trabalhos em 2017 e 2018. Constatou-se que das 53 dissertações destacamse com maior incidência: propostas de formação continuada (24\%), planejamento estratégico $(9 \%)$, diretrizes institucionais (9\%). Assim, foi possível identificar as maiores demandas e inquietações dos profissionais da educação, bem como os tipos de produtos que foram propostos para qualificar a atuação desses profissionais no trabalho.
\end{abstract}

Palavras-chave: mestrado profissional; pós-graduação; formação continuada; produtos educacionais.

\section{PRODUCTS OF A PROFESSIONAL MASTER IN EDUCATION: A STATE OF KNOWLEDGE}

\begin{abstract}
This study aimed to identify and analyze the educational products resulting from the Professional Master Course in Public Policy and Educational Management at the Universidade Federal de Santa Maria. It is an exploratory research, based on the state of knowledge of the dissertations available in the UFSM digital repository, classes that defended the work in 2017 and 2018. It was found that, of the 53 dissertations, stand out with the highest incidence: proposals for continuing education (24\%), strategic planning $(9 \%)$, guidelines $(9 \%)$. Thus, it was possible to identify the greatest demands and concerns of education professionals, as well as the types of products that were built to qualify the performance of these professionals at work.

Key-words: professional master's degree; postgraduate studies; continuing formation; educational products.
\end{abstract}

\footnotetext{
1 Universidade Federal de Santa Maria, Brasil. E-mail: cristianolanza@hotmail.com.

2 Universidade Federal de Santa Maria, Brasil. E-mail: simessina@gmail.com.

3 Universidade Federal de Santa Maria, Brasil. E-mail: marilenedallacorte@gmail.com.

4 Universidade Federal de Santa Maria, Brasil. E-mail: lorenamarequezan@yahoo.com

Regae: Rev. Gest. Aval. Educ. Santa Maria $\quad$ v. 9 n.18 Pub. contínua 2020

p. 1-14
} 


\section{Introdução}

A formação continuada oportuniza o compartilhamento de experiências, saberes, práticas pedagógicas, bem como a re-construção de conhecimentos. Dentre as modalidades de formação continuada inserem-se os mestrados profissionais, os quais se configuram como cursos stricto sensu voltados à qualificação dos profissionais em serviço, ou seja, com o foco no campo de atuação profissional. Além disso tais cursos priorizam promover a articulação integrada da formação profissional com entidades demandantes, estreitando as relações das instituições de ensino e de pesquisa com os diferentes setores públicos e privados de atuação profissional (Brasil, 2017).

No entendimento de André (2016) o mestrado profissional deve formar o pesquisador prático, ou seja, propiciar a constituição de sujeitos autônomos, que tenham opiniões e ideias próprias e que ao fazer uma leitura crítica do seu contexto de trabalho, saibam buscar referências e recursos para compreender essa realidade, delineando caminhos de atuação qualificada. Nesse sentido, pode-se afirmar que são cursos que têm o compromisso com a formação de profissionais para o enfrentamento das problemáticas relacionadas ao seu campo de trabalho, mas, também, com vistas ao desenvolvimento de pesquisas inovadoras e que contribuam para a qualificação dos espaços de atuação profissional.

Em relação aos mestrados profissionais na área educacional, estes se propõem a buscar soluções para problemáticas relacionadas às áreas de formação de professores, políticas públicas, gestão educacional, tanto no âmbito micro - escola -, quanto no âmbito macro - sistemas de ensino. Em outras palavras são cursos destinados à aplicação e geração de processos formativos e de investigação voltados aos problemas do cotidiano de professores, gestores e profissionais da educação (Fialho; Hetkowski, 2017).

No que se refere ao trabalho de conclusão, este tem como finalidade propor a qualificação do contexto investigado ou o enfrentamento de uma situação problemática, a partir do desenvolvimento de um produto educacional. Moreira e Nardi (2009), compreendem que os trabalhos finais dos mestrados profissionais configuram-se como relatos de experiências de implementação de estratégias ou produtos de natureza educacional, os quais adquirem caráter prático e estão voltados para a instrumentalização do ensino em determinado contexto social.

Nessa perspectiva, este estudo tem como objetivo identificar os desafios, bem como os produtos educacionais ou conhecimentos que foram propostos para qualificar os processos de gestão educacional e ou institucional na perspectiva da melhoria dos espaços de atuação profissional, tendo como lócus de pesquisa o Mestrado Profissional em Políticas Públicas e Gestão Educacional - MP/PPPG - da Universidade Federal de Santa Maria.

A presente pesquisa traz informações que poderão ser utilizadas para a própria avaliação do curso, bem como para sua qualificação, com vistas aos impactos educacionais gerados pelos produtos. Além disso, poderá inspirar outros produtos educacionais para os novos alunos do curso. 


\section{Percurso metodológico}

O estudo classifica-se como exploratório e descritivo, considerando os preceitos de uma pesquisa do estado do conhecimento das dissertações e seus respectivos produtos desenvolvidos. $O$ estado do conhecimento é uma metodologia que tem por base a identificação, o registro e a categorização que levem à reflexão da produção científica de um determinado tema e período, utilizando de diversas fontes como periódicos, teses ou dissertações (Morosini; Fernandes, 2014). Este estudo delimitou-se às dissertações defendidas em 2017 e 2018, referente às turmas ingressantes em 2015 e 2016 do Mestrado Profissional em Políticas Públicas e Gestão Educacional da Universidade Federal de Santa Maria, as quais se encontram disponíveis no repositório digital da UFSM. Também utilizou-se informações disponíveis na Plataforma Sucupira.

O estudo das dissertações seguiram as fases destacadas por Morosini e Fernandes (2014): leitura flutuante do corpus de análise para a identificação dos textos; estudo da bibliografia e análise de conteúdo. A partir da identificação das dissertações, procedeu-se a leitura dos resumos identificando-se os desafios dos contextos de atuação profissional, o tipo de produto educacional desenvolvido, o nível de ensino, bem como a sua distribuição ou abrangência geográfica. Tais informações foram organizadas e dispostas em quadros e tabelas para fins de análise.

\section{Os mestrados profissionais no âmbito da pós-graduação}

A formação continuada stricto sensu voltada ao campo profissional está prevista na regulamentação inicial da pós-graduação desde a década de 1960, por meio do parecer n. 977/65, do Conselho Federal de Educação, que já destacava que o mestrado tanto pode ser de pesquisa como profissional (Brasil, 1965). No entanto, o mestrado profissional enquanto modalidade de formação institucionalizada, no contexto da prática, é relativamente recente na pós-graduação brasileira, considerando que sua institucionalização ocorreu mediante a portaria n. 47, de 17 de outubro de 1995, da Coordenação de Aperfeiçoamento de Pessoal de Nível Superior (Brasil, 1995).

A partir das regulamentações os mestrados profissionais passaram a ter a validade nacional do diploma condicionada à avaliação da Capes, ao reconhecimento pelo Conselho Nacional de Educação e à homologação pelo Ministério da Educação. Também, são conferidos ao diplomado prerrogativas e grau idênticos aos dos que concluem o mestrado acadêmico, inclusive no que se refere ao exercício da docência.

Com relação aos seus objetivos, o mestrado profissional visa a capacitar e qualificar profissionais para atender demandas sociais, organizacionais e do mundo do trabalho; promover a articulação integrada da formação profissional com entidades demandantes de naturezas diversas, a fim de melhorar a eficiência e eficácia nas organizações públicas e privadas, através da geração e aplicação de processos de inovação para a solução de problemas (Brasil, 2017).

Latini et al (2011) consideram que a proposta do mestrado profissional tem como característica o desenvolvimento de pesquisas a partir de uma perspectiva interna do contexto analisado, o que propicia a redução do distanciamento social presente até então na relação entre o sujeito e os que se constituem em seu objeto de investigação. $\mathrm{Na}$ mesma linha de pensamento, Gatti (2014) faz uma distinção entre pesquisa acadêmica e pesquisa aplicada, sendo esta última compreendida por ela como pesquisa engajada. 
Segundo a autora o propósito da pesquisa acadêmica é evidenciar realidades a partir de uma perspectiva teórica, validar teorias, criar novo ramo explicativo, identificar lacunas na teoria, propondo outra ótica explicativa. Já a pesquisa engajada tem a realidade empírica como ponto de partida e de chegada e visa a evidenciar fatos específicos, pela compreensão de situações localizadas, buscando soluções e propondo alternativas (Gatti, 2014).

Com base no conceito de pesquisa engajada, pode-se afirmar que os acadêmicos dos mestrados profissionais têm o desafio de empreender pesquisas implicadas e aplicadas com rigor teórico-metodológico para que possam ampliar sua compreensão do contexto investigado como pesquisadores em ambiente natural de trabalho e, posteriormente, desenvolver produtos para contribuir ou intervir nas realidades de atuação profissional. Além das diferenças relativas às pesquisas, Fischer (2005) destaca que os mestrados profissionais podem variar quanto aos públicos a quem se destinam, quanto à estrutura do curso, ao local e tempo de duração, à exigência de dedicação do estudante e à natureza do ensino.

Em relação ao público-alvo alguns cursos apresentam um formato mais generalista, enquanto que outros se configuram como cursos mais focalizados. De acordo com Fischer (2005) os mestrados profissionais mais generalistas têm como objetivo formar profissionais multiqualificados em nível estratégico, propondo-se a fazer com que o aluno reflita sobre suas práticas de forma crítica. Como exemplo de mestrados com essas características encontram-se os cursos na área de gestão.

Os mestrados mais focalizados objetivam formar profissionais para áreas de atuação específicas, possibilitando especialização e maior instrumentalidade para lidar com problemas da profissão. Estão enquadrados nesses casos os mestrados em Engenharia e Odontologia, entre outros (Fischer, 2005). Além desses modelos, Fischer (2005) aponta a existência de um terceiro caso: são os mestrados híbridos como, por exemplo, o mestrado profissional em ensino desenvolvido nas áreas de Ciências e Matemática, o qual conjuga a teoria que se ensina à organização de condições para a prática docente. Também, verificou-se pelo mapeamento das características e foco dos mestrados profissionais na área da educação que muitos cursos estão relacionados a temáticas mais específicas como, por exemplo, alfabetização e letramento, ensino de línguas, educação matemática, ensino de história, entre outras perspectivas.

Considerando esses diferentes modelos, pode-se inferir que os produtos finais desses cursos possivelmente assumirão especificidades relacionadas à suas temáticas e aderências com respectivos contextos de atuação profissional, tendo em vista os objetivos, as características e particularidades metodológicas de cada curso.

\section{O Mestrado Profissional em Políticas Públicas e Gestão Educacional da UFSM}

Os primeiros programas na modalidade de mestrado profissional destinados à área da educação emergiram em instituições públicas, inicialmente na Universidade Federal de Juiz de Fora, em 2009, com a criação do Mestrado em Gestão e Avaliação da Educação Pública e, posteriormente, na Universidade do Estado da Bahia em 2011, a partir da instituição do Mestrado em Gestão e Tecnologias Aplicadas à Educação (Fialho; Hetkowski, 2017). 
$\mathrm{Na}$ UFSM os cursos de pós-graduação voltados para área educacional, nessa modalidade, foram instituídos em 2012, com a criação do Mestrado Profissional em Tecnologias Educacionais em Rede e ampliou-se com a participação do Mestrado Profissional em Ensino de História em Rede Nacional, em 2013. Em 2015, a partir da identificação da necessidade da oferta de mais um curso de pós-graduação voltado aos profissionais da educação, criou-se o Mestrado Profissional em Políticas Públicas e Gestão Educacional.

Assim, o curso foi instituído em 26 de março de 2015 na perspectiva de produzir conhecimentos relacionados à formação de qualidade de profissionais da educação, para potencializar o desenvolvimento de práticas interventivas, por meio da ação-reflexãoação, com conhecimento, criticidade, comprometimento e competência, com vistas ao exercício da prática profissional pautado pela busca da inovação e valorização da experiência profissional (UFSM, 2015a).

Com sede no Centro de Educação da UFSM o curso surgiu da experiência dessa unidade na área de políticas públicas e gestão educacional, inicialmente com a oferta do curso de Pedagogia, em 1965 e, posteriormente, por meio da pós-graduação em Educação em nível de mestrado, em 1971. O curso foi idealizado por um grupo de docentes do Centro de Educação o qual percebeu a carência de oferta de cursos de mestrado que atendam ao processo de formação continuada de egressos que atuam na área da educação na região de abrangência de Santa Maria (UFSM, 2015b).

O projeto-pedagógico de curso do MP/PPPG tem como objetivo geral promover formação continuada dos profissionais da educação, a fim de qualificar a sua atuação em processos de gestão administrativa, financeira e pedagógica das redes/sistemas e contextos educativos (UFSM, 2015c). Para tal, propõe um conjunto de temas de estudo e reflexão, a partir da investigação-ação inserida na Educação Básica e na Ensino superior, em suas políticas públicas e processos de gestão educacional, com base em duas linhas de pesquisa. Na linha de pesquisa 1 - Políticas e gestão da educação básica e superior prioriza-se desenvolver pesquisas aplicadas e projetos de intervenção nos contextos social e econômico das políticas públicas educacionais em sentido amplo, ou seja, redes de ensino e sistemas de ensino, tendo como foco principal a formação qualificada de gestores. $\mathrm{Na}$ linha de pesquisa 2 - Gestão pedagógica e contextos educativos busca desenvolver pesquisas aplicadas e projetos de intervenção na gestão pedagógica e contextos educativos, em especial na gestão escolar.

Em relação ao perfil do egresso o MP/PPPG espera que obtenha atuação qualificada e inovadora em processos de gestão educacional e institucional no contexto das redes, sistemas e respectivos contextos educativos, a partir da utilização de materiais e recursos educacionais produzidos em sua pesquisa. Com relação ao trabalho final este pode assumir diferentes formatos como: texto dissertativo, material didático ou midiático, projeto ou plano de trabalho de intervenção em contexto educativo, ou outro, desde que corrobore os princípios e objetivos do curso (UFSM, 2015d).

A estrutura curricular do MP/PPPG tem como campo estruturante a pesquisa aplicada e implicada em múltiplos contextos educacionais e está organizada em três núcleos articulados entre si, a fim de promover a interlocução entre os professores e os estudantes, por meio de projetos de pesquisa aplicada e implicada que são desenvolvidos nos diversos contextos inter-relacionados à educação básica ou superior. 
Assim sendo, o núcleo básico prioriza promover a formação de base voltada ao estudo teórico-prático, o posicionamento crítico-reflexivo e a compreensão da interrelação administrativa, financeira, curricular, pedagógica das políticas públicas da gestão educacional, escolar e universitária (UFSM, 2015e). O núcleo integrador propicia ao estudante o desenvolvimento de processos de pesquisa aplicada e implicada ao seu tema de interesse, com vistas a promover a articulação entre o conhecimento e os saberes teórico-práticos, a partir da visão diagnóstica, da análise e da atuação profissional no âmbito da linha de pesquisa escolhida (UFSM, 2015f). O rol de disciplinas organizadas por tópicos específicos que tratam dos temas relacionados às especificidades das linhas de pesquisa compreende o núcleo de aprofundamento.

Além dos núcleos mencionados poderá haver a necessidade da proposição de novas disciplinas e seminários pertinentes às temáticas emergentes dos projetos de pesquisa dos estudantes. Destaca-se que o estudante poderá escolher tantas disciplinas quantas possam contribuir para o desenvolvimento do seu trabalho final, bem como pode buscar disciplinas em outros programas de pós-graduação na UFSM ou em outras instituições. A matrícula nas disciplinas de Seminário de Orientação I e Seminário de Orientação II é obrigatória e, ainda, é exigida no mínimo uma Língua Estrangeira Moderna, cujo comprovante deverá ser apresentado até a qualificação do projeto de pesquisa (UFSM, 2015g).

Com essa formatação o MP/PPPG configura-se como um curso de formação continuada que busca potencializar oportunidades para que o profissional, que atua na área da educação, reconheça-se no seu contexto específico de atuação, identifique as necessidades e especificidades dessa realidade e de seus envolvidos, bem como busque, com conhecimento e reflexividade crítica, a proposição de estratégias de ação qualificadas e inovadoras no exercício da profissão.

\section{Análise e discussão dos resultados}

Os mestrados profissionais, na área educacional, possibilitam a partir das pesquisas desenvolvidas e dos produtos educacionais construídos, soluções, encaminhamentos ou intervenções nos contextos educativos. Conforme afirmam Zaidan, Ferreira e Kawasaki (2018), muitos professores já criam alternativas na prática, entretanto, em alguns casos, devido à complexidade da problemática, há a necessidade de experimentação e elaboração teórica, a fim de que o problema seja equacionado. Em outras palavras, por meio da pesquisa da própria prática com embasamento teórico, os produtos educacionais são desenvolvidos de acordo com a necessidade ou complexidade do problema investigado.

Tabela 1 -

Relação de produtos por ano de conclusão

\begin{tabular}{c|c}
\hline Ano de conclusão & Número de produtos \\
\hline 2017 & 27 \\
\hline 2018 & 26 \\
\hline Total & 53 \\
\hline
\end{tabular}

Fonte: autores (2019). 
Para melhor visualização dos 53 produtos educacionais desenvolvidos optou-se pela elaboração de uma tabela com a descrição do tipo e a quantidade de cada produto.

Tabela 2 -

Tipo e quantitativo dos produtos educacionais desenvolvidos.

\begin{tabular}{l|c}
\multicolumn{1}{c|}{ Tipo de produto } & Quantidade \\
\hline Círculos dialógicos & 3 \\
\hline Diagnóstico & 5 \\
\hline Diretrizes & 2 \\
\hline E-book & 1 \\
\hline Modelo de distribuição orçamentária & 1 \\
\hline Norma técnica & 5 \\
\hline Planejamento estratégico & 1 \\
\hline Plano de ações & 2 \\
\hline Plano de estudos & 1 \\
\hline Projeto de alteração de lei & 1 \\
\hline Projeto de apoio à saúde estudantil & 2 \\
\hline Projeto de educação integral & 1 \\
\hline Proposta de organização do trabalho docente & 1 \\
\hline Projeto de gestão do conhecimento & 1 \\
\hline Projeto de qualidade de vida docente & 1 \\
\hline Projeto de reformulação de PPP & 1 \\
\hline $\begin{array}{l}\text { Projeto de unidade administrativa (Núcleo de } \\
\text { Extensão em Línguas Estrangeiras) }\end{array}$ & 13 \\
\hline Propostas de formação continuada & 1 \\
\hline Protocolo de sugestões & 3 \\
\hline Relatório de análise & 1 \\
\hline Site Institucional com minuta de instrução & 1 \\
\hline $\begin{array}{l}\text { Checklist sobre processo de Avaliação de } \\
\text { Cursos de Graduação }\end{array}$ & 1 \\
\hline Paper sobre elementos & 1 \\
metodológicos do Enem & \\
\hline Proposta de princípios para a gestão do & 1 \\
\hline Proposta de Círculo da Paz & 1 \\
\hline Metodologia de produção compartilhada de & 1 \\
\hline Projeto de ensino & 1 \\
\hline & \\
\hline
\end{tabular}

Fonte: autores (2019).

Conforme disposto na tabela 2 percebe-se que as produções científicas e técnicas decorrentes das pesquisas do MP/PPPG compreendem diferentes tipos ou formatos, dentre os quais destacam-se com maior incidência: propostas de formação continuada (24\%), planejamento estratégico (9\%), diretrizes $(9 \%)$, entre outros formatos. Ressalta-se que todos os 53 produtos identificados no estado do conhecimento, referente ao período de 2017 a 2018, constituem-se em possibilidades para a implantação de mudanças, inovações e qualificação das práticas educacionais e dos processos de gestão nas redes ou sistemas em todos níveis de ensino. Entretanto, por questões teórico-metodológicas,
Regae: Rev. Gest. Aval. Educ.
Santa Maria
v. 9
n. 18
Pub. contínua 2020
p. $1-14$ 
optou-se por analisar os tipos de produtos com maior incidência. Assim sendo, tais produtos foram organizados em três quadros contendo o tipo de produto, a descrição sintética e o nível de educação para o qual foi elaborado.

Quadro 1 -

Tipo de produto, descrição sintética e nível de educação.

\begin{tabular}{|c|c|c|}
\hline Tipo de produto & Descrição sintética & Nível \\
\hline \multirow{13}{*}{$\begin{array}{l}\text { Proposta de } \\
\text { formação } \\
\text { continuada }\end{array}$} & $\begin{array}{l}\text { Formação de professores para a construção de práticas } \\
\text { pedagógicas de alfabetização diante dos desafios da } \\
\text { progressão continuada de alunos com defasagem nos } \\
\text { anos iniciais do ensino fundamental. }\end{array}$ & $\begin{array}{l}\text { Ensino } \\
\text { fundamental }\end{array}$ \\
\hline & $\begin{array}{l}\text { Proposta de formação compartilhada para o ensino } \\
\text { fundamental, visando ao envolvimento, a análise e a } \\
\text { reflexão de processos formativos da docência no espaço } \\
\text { escolar. }\end{array}$ & $\begin{array}{l}\text { Ensino } \\
\text { fundamental }\end{array}$ \\
\hline & $\begin{array}{l}\text { Encontros formativos com educadoras da educação } \\
\text { infantil. }\end{array}$ & $\begin{array}{c}\text { Educação } \\
\text { infantil }\end{array}$ \\
\hline & $\begin{array}{l}\text { Formação continuada voltada ao reconhecimento e } \\
\text { valorização de personagens negros na literatura infantil. }\end{array}$ & $\begin{array}{c}\text { Educação } \\
\text { infantil }\end{array}$ \\
\hline & $\begin{array}{l}\text { Proposta de Unidades Formativas sobre práticas de } \\
\text { produção do professor alfabetizador, participante do Pacto } \\
\text { Nacional de Alfabetização na Idade Certa. }\end{array}$ & $\begin{array}{l}\text { Ensino } \\
\text { fundamental }\end{array}$ \\
\hline & $\begin{array}{l}\text { Proposta de formação continuada para professores de } \\
\text { uma escola estadual como estratégia para reestruturação } \\
\text { do trabalho escolar no enfrentamento dos elementos } \\
\text { intensificadores do mal estar docente. }\end{array}$ & Ensino médio \\
\hline & $\begin{array}{l}\text { Proposta de formação para profissionais de apoio que } \\
\text { atuam com alunos caracterizados como público-alvo da } \\
\text { educação especial na rede municipal. }\end{array}$ & $\begin{array}{l}\text { Ensino } \\
\text { fundamental }\end{array}$ \\
\hline & $\begin{array}{l}\text { Desenvolvimento de uma formação com o tema Conselho } \\
\text { Escolar como espaço de participação e co- } \\
\text { responsabilização de seus participantes. }\end{array}$ & $\begin{array}{l}\text { Ensino } \\
\text { fundamental }\end{array}$ \\
\hline & $\begin{array}{l}\text { Curso híbrido de formação continuada para técnicos e } \\
\text { conselheiros municipais de educação. }\end{array}$ & $\begin{array}{c}\text { Ensino } \\
\text { fundamental }\end{array}$ \\
\hline & $\begin{array}{l}\text { Encontros formativos sobre o tema espaços e tempos na } \\
\text { educação infantil, bem como a produção de um livro com } \\
\text { o registro das discussões destes encontros. }\end{array}$ & $\begin{array}{l}\text { Educação } \\
\text { infantil }\end{array}$ \\
\hline & $\begin{array}{l}\text { Programa de formação continuada em serviço para } \\
\text { professores de séries iniciais de uma escola estadual, } \\
\text { visando promover o compartilhamento de experiências } \\
\text { sobre o trabalho escolar. }\end{array}$ & $\begin{array}{c}\text { Ensino } \\
\text { fundamental }\end{array}$ \\
\hline & $\begin{array}{l}\text { Formação para professores com vistas a qualificar o olhar } \\
\text { político e o trabalho realizado por docentes que atuam } \\
\text { com crianças em idade de educação infantil. }\end{array}$ & $\begin{array}{l}\text { Educação } \\
\text { infantil }\end{array}$ \\
\hline & $\begin{array}{l}\text { Formação sobre o plano de ações articuladas e a gestão } \\
\text { educacional/democrática com professores e gestores das } \\
\text { redes municipais da Associação dos municípios da zona } \\
\text { de produção do RS. }\end{array}$ & $\begin{array}{l}\text { Ensino } \\
\text { fundamental }\end{array}$ \\
\hline
\end{tabular}

Fonte: autores (2019).

De acordo com o disposto no quadro1 percebe-se que a formação continuada representa a maior demanda dos profissionais da educação básica, especialmente daqueles que atuam no ensino fundamental. Em relação aos produtos desenvolvidos no âmbito do ensino fundamental, estes enfocam desafios e temáticas como: progressão
Regae: Rev. Gest. Aval. Educ.
Santa Maria
v. 9
ก. 18
Pub. contínua 2020
p. 1-14 
continuada de alunos com defasagem nos anos iniciais; processos formativos da docência no espaço escolar; práticas de produção do professor alfabetizador que participa do Pacto Nacional de Alfabetização na Idade Certa; profissionais de apoio que atuam na educação especial; participação e co-responsabilização dos participantes do conselho escolar; formação para técnicos e conselheiros municipais de educação; formação em serviço para professores de séries iniciais; gestão educacional/democrática.

Apresenta-se, também, por meio do quadro 2, o tipo de produto caracterizado como planejamento estratégico.

Quadro 2 -

Tipo de produto, descrição sintética e nível de educação.

\begin{tabular}{|l|l|l|}
\hline Tipo de produto & \multicolumn{1}{|c|}{ Descrição sintética } & \multicolumn{1}{|c|}{ Nível } \\
\hline & $\begin{array}{l}\text { Planejamento voltado para educadores do ensino } \\
\text { médio de uma escola rural destinado a converter } \\
\text { intenções em realizações, na perspectiva de consolidar } \\
\text { boas práticas, fortalecer as relações humanas e de } \\
\text { trabalho educativo. }\end{array}$ & Ensino médio \\
\cline { 2 - 3 } & $\begin{array}{l}\text { Planejamento desenvolvido com vistas a minimizar a } \\
\text { evasão das alunas dos cursos de licenciatura noturno } \\
\text { do Centro de Educação da UFSM. }\end{array}$ & Ensino superior \\
\cline { 2 - 4 } estratégico & $\begin{array}{l}\text { Planejamento com vistas a re-significar os processos } \\
\text { de gestão e atingir a qualidade da educação do campo } \\
\text { através da democratização e do resgate do ser } \\
\text { humano. }\end{array}$ & Ensino fundamental \\
\cline { 2 - 4 } & $\begin{array}{l}\text { Planejamento destinado à rearticulação das ações de } \\
\text { gestão com vistas a reduzir a evasão nos cursos de } \\
\text { licenciatura do Instituto Federal Farroupilha, campus } \\
\text { São Vicente do Sul, RS. }\end{array}$ & Ensino superior \\
\cline { 2 - 4 } & $\begin{array}{l}\text { Plano de gestão escolar do bloco pedagógico com } \\
\text { base na análise das demandas e dos desafios gestão } \\
\text { escolar acerca da normativa de progressão continuada } \\
\text { nos anos iniciais do ensino fundamental. }\end{array}$ & Ensino fundamental \\
\hline
\end{tabular}

Fonte: Elaborado pelos autores (2019).

O produto planejamento estratégico consiste em um instrumento cuja amplitude engloba a missão, visão, valores e os objetivos estratégicos da instituição. Em vista disso, torna-se relevante tanto para as instituições de educação básica quanto de ensino superior, entretanto, vale lembrar que a consecução dos objetivos elencados no planejamento dependerá do engajamento e comprometimento do coletivo.

No âmbito da educação básica constatou-se que foram elaborados planejamentos estratégicos destinados a fortalecer as relações humanas e de trabalho educativo em uma escola rural do ensino médio; re-significar os processos de gestão a fim de atingir a qualidade da educação do campo por meio da democratização e do resgate do ser humano e, ainda, foi elaborado um planejamento estratégico voltado para a gestão escolar do bloco pedagógico, a fim de atender a normativa de progressão continuada nos anos iniciais do ensino fundamental. 
Em relação ao ensino superior verificou-se a elaboração do planejamento estratégico para a definição de estratégias e rearticulação das ações de gestão, com vistas a minimizar o problema de evasão nos cursos de licenciatura. A relevância de tal produto merece ser destacada uma vez que a evasão nas instiuições educacionais, em todos os níveis, causam prejuízos econômicos, financeiros e sociais. Nesse sentido, a proposta de um produto que tenha por finalidade estabelecer ações para mitigar tal problema é benéfica para todos os envolvidos. Além dos tipos de produtos descritos, apresenta-se no quadro 3 o produto educacional com formato de diretrizes.

Quadro 3 -

Tipo de produto, descrição sintética e nível de educação.

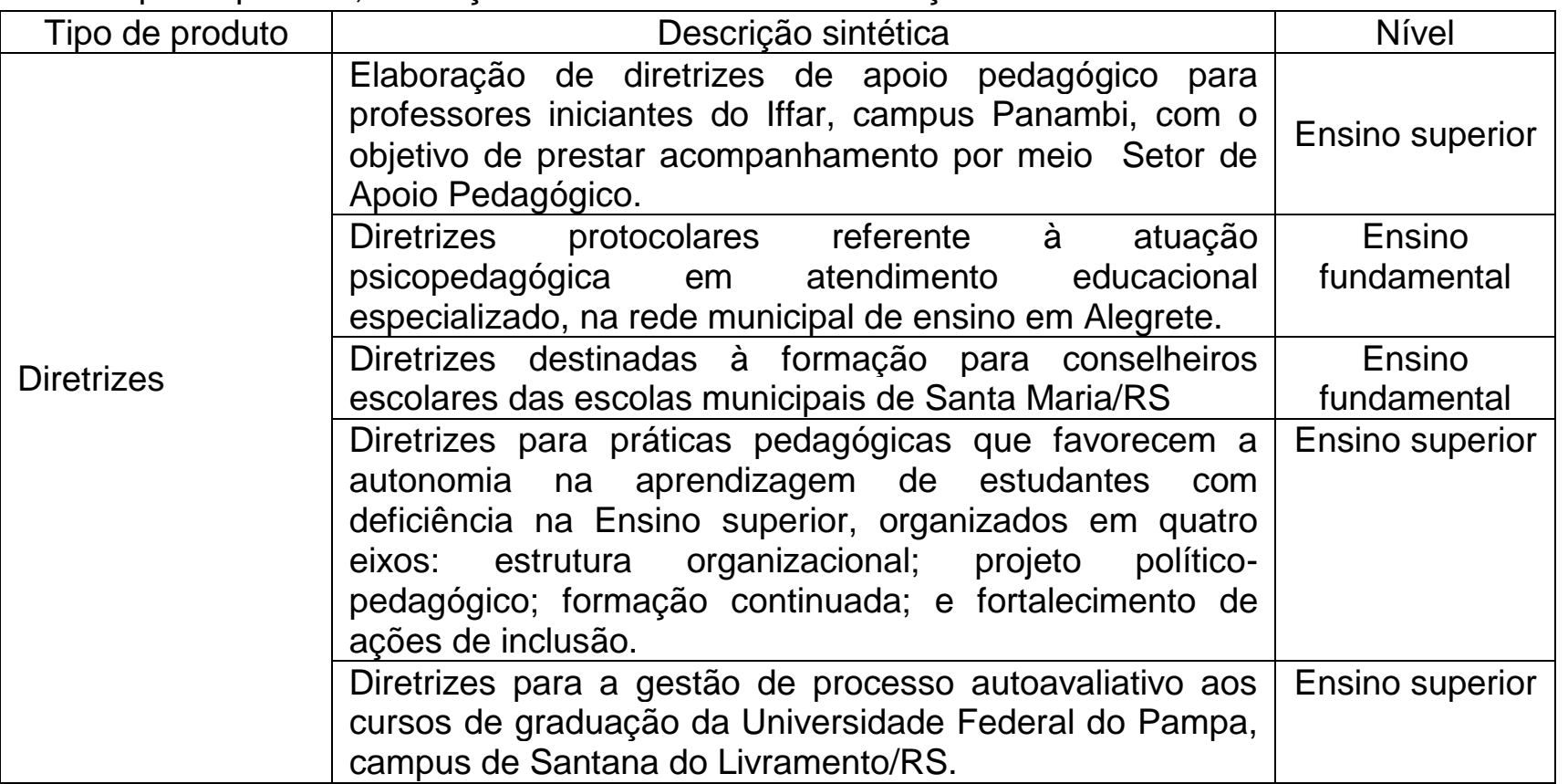

Fonte: autores (2019).

Percebe-se que as produções científicas e técnicas decorrentes das pesquisas de mestrado profissional possuem o diferencial de possibilitar a intervenção, em alguns casos, imediata no contexto educativo, a exemplo das formações continuadas, mas também podem constituir-se em planos ou orientações para serem implementadas ao final da pesquisa. Assim sendo, no quadro 3 pode-se constatar que foram elaboradas diretrizes que contemplam ações de apoio pedagógico aos professores iniciantes; orientações sobre práticas pedagógicas que favorecem a autonomia na aprendizagem de estudantes com deficiência, bem como diretrizes voltadas ao processo autoavaliativo de cursos de graduação.

No âmbito da educação básica as diretrizes elaboradas enfocaram a atuação psicopedagógica em atendimento educacional especializado, bem como a formação para conselheiros escolares na rede municipal de ensino.

Com base nos três tipos de produtos analisado e a partir do levantamento dos demais produtos constante no quadro 1 , infere-se que a inserção social e 0 impacto de alguns produtos dependerão desde uma mudança de comportamento dos atores envolvidos até uma mudança de cultura organizacional. 
Além dos produtos com maior incidência e seus respectivos níveis de educação, apresenta-se na tabela 3 um panorama geral sobre os níveis de educação mais priorizados nas pesquisas analisadas.

Tabela 3 -

Distribuição dos produtos por nível de educação.

\begin{tabular}{|c|c|c|}
\hline \multicolumn{2}{|c|}{ Nível } & Quantidade \\
\hline \multirow{3}{*}{ Educação básica } & Educação infantil & 12 \\
\hline & Ensino fundamental & 19 \\
\hline & Ensino médio & 8 \\
\hline \multicolumn{2}{|l|}{ Subtotal } & 39 \\
\hline \multicolumn{2}{|l|}{ Ensino superior } & 14 \\
\hline \multicolumn{2}{|l|}{ Total } & 53 \\
\hline
\end{tabular}

Fonte: autores (2019).

Conforme observa-se na tabela 3 os dois níveis de educação foram contemplados, entretanto, a maior parte dos produtos (74\%) foi desenvolvida no âmbito da educação básica, estando em convergência com o Plano Nacional de Pós-Graduação 2011-2020, que explicita a educação básica como "um assunto estratégico" (PNPG, 2010, p. 158).

Para Zaidan, Ferreira e Kawasaki (2018) a elaboração pelos professores de produtos educacionais devolve à comunidade conhecimentos, saberes, resultados e objetos de ensino que contribuem para a própria prática pedagógica e para a instituição educativa. Nesse sentido, tem-se a expectativa de que os produtos elaborados possam contribuir para promover mudança, inovação e qualificação das práticas educacionais, bem como dos processos de gestão nas redes ou sistemas e instituições escolares em todos os níveis de ensino.

Tabela 4 -

Distribuição dos produtos educacionais por municípios/RS.

\begin{tabular}{l|c}
\hline \multicolumn{1}{c|}{ Municípios } & Número de produtos \\
\hline Santa Maria & 34 \\
\hline Santa Cruz do Sul & 1 \\
\hline São Gabriel & 1 \\
\hline Alegrete & 2 \\
\hline São Pedro do Sul & 1 \\
\hline Jóia & 1 \\
\hline São Vicente do Sul & 1 \\
\hline Restinga Seca & 1 \\
\hline Uruguaiana & 1 \\
\hline Panambi & 1 \\
\hline Santana do Livramento & 1 \\
\hline Itaqui & 1 \\
\hline Toropi & 1 \\
\hline Rondinha & 1 \\
\hline Cachoeira do Sul & \\
\hline
\end{tabular}

Fonte: autores (2019). 
A abrangência geográfica das produções referente aos anos de 2017 e 2018 revela o predomínio dos produtos educacionais voltados para a cidade de Santa Maria e região Central do Rio Grande do Sul. Tal fato corrobora a necessidade de formação continuada dos profissionais da educação que atuam na rede pública e em IES e que estão inseridos nesse contexto geográfico, conforme previsto no PPC do MP/PPPG, bem como manifestado, tanto pela Secretaria Municipal de Educação de Santa Maria, quanto pela $8^{a}$ Coordenadoria Regional de Educação (UFSM, 2015e). Destaca-se, também, o desafio do MP/PPPG em ampliar sua abrangência e escopo em termos de inserção social e acesso ao curso, considerando a necessidade constante de qualificação dos profissionais da educação.

\section{Considerações finais}

A pesquisa propiciou um panorama geral dos produtos criados no âmbito do MP/PPPG da UFSM, bem como possibilitou identificar as principais demandas dos profissionais que atuam nos diferentes contextos educativos. Foram elaborados 53 produtos, contemplando temas como formação continuada de professores, gestão administrativa, financeira e pedagógica e gestão educacional, entre outros, com predominância de produtos voltados para a formação continuada. Tal fato denota que a formação continuada tem importância na vida dos profissionais que foram investigados em seus contextos de trabalho, ou seja, para além de suas atividades cotidianas eles estão buscando aprimorar seus conhecimentos e suas práticas.

Em relação aos produtos voltados para a gestão - projeto de ensino, plano de ação ou planejamento estratégico - cabe destacar a sua importância, pois a educação é um processo dinâmico, complexo e evolutivo que deve acontecer de forma organizada e sistemática, e depende, entre outros fatores, de uma equipe de colaboradores alinhada aos objetivos da instituição (Lück, 2009). Nesse sentido, o planejamento estratégico constitui-se em um instrumento que possibilita aos profissionais da educação o alinhamento de suas ações pedagógicas e administrativas aos objetivos da instituição de ensino.

Quanto ao nível de educação constatou-se que, tanto a educação básica, quanto o ensino superior foram contemplados nas propostas, entretanto, o maior número de produtos foram desenvolvidos no âmbito da educação básica, contribuindo para a qualificação dos profissionais que nela atuam e respectivos contextos educativos, entre eles escolas de educação infantil, escolas de ensino fundamental, escolas de ensino médio. Assim, esta pesquisa possibilitou identificar, a partir das temáticas predominantes, as maiores demandas e inquietações dos profissionais da educação, bem como os tipos de produtos que foram construídos para qualificar a atuação desses profissionais em seus contextos de trabalho.

Para futuras pesquisas pretende-se investigar quais desses produtos foram ou estão sendo implementados, bem como os desafios enfrentados pelos egressos, coordenação do MP/PPPG e instituição de vínculo profissional do egresso nesse processo.

\section{Referências}

ANDRÉ, Marli. A formação do pesquisador da prática pedagógica. Plurais - Revista Multidisciplinar, Salvador, v. 1, n. 1, 2018, p. 30-41. 
BRASIL. Parecer n. 977, de 3 de dezembro de 1965. Conceitos de pós graduação, mestrado e doutorado; aconselha jornada de 360 a 450 horas anuais de atividades coletivas; autorização específica para os cursos stricto sensu. Coordenação de Aperfeiçoamento de Pessoal de Nível Superior. Disponível em: http://www.capes.gov.br/images/stories/download/legislacao/Parecer_CESU_977_1965.p df. Acesso em 7 mar. 2019.

BRASIL. Plano nacional de pós-graduação (PNPG 2011-2020). Brasília: Capes, 2010. Disponível em https://www.capes.gov.br/images/stories/download/Livros-PNPG-Volume-IMont.pdf. Acesso em 5 jul. 2019.

BRASIL. Portaria n. 47, de 17 de outubro de 1995. Procedimentos apropriados à recomendação, acompanhamento e avaliação de cursos de mestrado dirigidos à formação profissional. Coordenação de Aperfeiçoamento de Pessoal de Nível Superior. Disponível em http://ojs.rbpg.capes.gov.br/index.php/rbpg/article/view/87/83. Acesso em 8 abr. 2019.

BRASIL. Portaria n. 389, de 23 de março de 2017. Dispõe sobre o mestrado e doutorado profissional no âmbito da pós-graduação stricto sensu. Coordenação de Aperfeiçoamento de Pessoal de Nível Superior. Disponível em http://www.capes.gov.br/images/stories/download/legislacao/24032017-PORTARIA-No389-DE-23-DE-MARCO-DE-2017.pdf. Acesso em 8 abr. 2019.

DALLA CORTE, Marilene Gabriel; SARTURI, Rosane. Políticas públicas para a formação de professores e contextos emergentes na Ensino superior. Revista Internacional de Ensino superior, Campinas, v. 1, n. 2, 2015, p. 160-181.

FIALHO, Nadia Hage; HETKOWSKI, Tânia Maria. Mestrados profissionais em educação: novas perspectivas da pós-graduação no cenário brasileiro. Educar em Revista, Curitiba, v. 33, n. 63, 2017, p. 19-34.

FISCHER, Tânia. Mestrado profissional como prática acadêmica. Revista Brasileira de Pós-Graduação, Brasília, v. 2, n. 4, 2005, p. 24-29.

FREIRE. Paulo. A pedagogia da autonomia: saberes necessários à prática educativa. São Paulo: Paz e Terra, 1996.

GATTI, Bernardete Angelina. A pesquisa em mestrados profissionais. FÓRUM DE MESTRADOS PROFISSIONAIS EM EDUCAÇÃO, 1, 2014. Anais ... Salvador: Uneb, 2014.

GIL, Antônio Carlos. Como elaborar projetos de pesquisa. São Paulo: Atlas. 2002.

LATINI, Rose Mary et al. Análise dos produtos de um mestrado profissional da área de Ensino de Ciências e Matemática. Ensino, Saúde e Ambiente, Niterói, v. 4, n. 2, 2011, p. 45-57.

LÜCK, Heloísa. Dimensões da gestão escolar e suas competências. Curitiba: Positivo, 2009.

MOREIRA, Marco Antônio; NARDI, Roberto. O mestrado profissional na área de ensino de Ciências e Matemática: alguns esclarecimentos. Revista Brasileira de Ensino de Ciência e Tecnologia, v. 2, n. 3, 2009, p. 1-9.

MOROSINI, Marília Costa; FERNANDES, Cleoni Maria Barboza. Estado do conhecimento: conceitos, finalidades e interlocuções. Educação por Escrito, Porto Alegre, v. 5, n. 2, 2014, p. 154-164. 
UFSM. Projeto pedagógico de curso Mestrado Profissional em Políticas Públicas e Gestão Educacional. Santa Maria: UFSM, 2015. Disponível em http://w3.ufsm.br/pppg/wpcontent/uploads/2016/03/PPC MESTRADO-PROFISSIONAL 2015.pdf. Acesso em 9 abr. 2019.

ZAIDAN, Samira; FERREIRA, Maria Cristina Costa; KAWASAKI, Terezinha Fumi. A pesquisa da própria prática no mestrado profissional. Plurais - Revista Multidisciplinar, Salvador, v. 3, n. 1, p. 88-103, 2018.

Cristiano Lanza Savegnago é graduado em Administração e servidor técnicoadministrativo na Universidade Federal de Santa Maria.

Orcid: https://orcid.org/0000-0002-7781-4040.

Endereço: Rua Francisco Giuliani, 1246 - 97200-000 - Restinga Seca - RS - Brasil.

E-mail: cristianolanza@hotmail.com.

Simone da Rosa Messina Gomez é licenciada em Ciências Biológicas e servidor técnico-administrativo na Universidade Federal de Santa Maria.

Orcid: https://orcid.org/0000-0003-1666-8016.

Endereço: RST 287, 6400/102A - 97105-030 - Santa Maria - RS - Brasil.

E-mail: simessina@gmail.com.

Marilene Gabriel Dalla Corte é professora na Universidade Federal de Santa Maria.

Orcid: https://orcid.org/0000-0001-8272-2944.

Endereço: Estrada Municipal Ângelo Berleze, 565 - 97095-640 - Santa Maria - RS Brasil.

E-mail: marilenedallacorte@gmail.com.

Lorena Inês Peterini Marquezan é professora na Universidade Federal de Santa Maria.

Orcid: https://orcid.org/0000-0001-6672-2258.

Endereço: Rua Felix Mainard, 180 - 97110-633 - Santa Maria - RS - Brasil.

E-mail: lorenamarequezan@yahoo.com.

Recebido em 18 de outubro de 2019.

Aceito em 22 de dezembro de 2019.

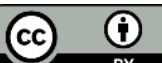

